\title{
Induction chemotherapy in patients with resectable head and neck squamous cell carcinoma: a meta-analysis
}

\author{
Jie Ma ${ }^{\dagger}$, Ying Liư ${ }^{\dagger}$, Xi Yang, Chen-ping Zhang, Zhi-yuan Zhang and Lai-ping Zhong ${ }^{*}$
}

\begin{abstract}
Background: Induction chemotherapy has been investigated as a possible strategy to shrink or downstage locally advanced head and neck cancers, providing opportunity to remove the lesions completely after induction chemotherapy, especially in the patients with resectable advanced disease. The aim of this study was to investigate the definitive effect of induction chemotherapy in patients with resectable head and neck squamous cell carcinoma.

Methods: A meta-analysis of randomized trials (1965-2011) was performed on the impact of induction chemotherapy on survival, disease control, and toxicity in this population of patients. Kaplan-Meier curves were read by Engauge-Digitizer. Data combining was performed using RevMan.

Results: Fourteen trials (2099 patients) were involved in this analysis. There was no significant difference on overall survival, disease free survival, or locoregional recurrence between the patients treated with and without induction chemotherapy $(P>0.05)$. However, the patients treated with induction chemotherapy had a lower rate of distant metastasis by $8 \%(95 \%$ confidence interval $1 \%-16 \%, P=0.02)$ than those treated without induction chemotherapy. In patients with laryngeal cancer, comparing to radical surgery, the larynx could be preserved in responders to induction chemotherapy without survival decease $(P>0.05)$. Induction chemotherapy-associated death was 0\%-5\%.

Conclusions: Based on the results above, there is a significant benefit of induction chemotherapy on decreasing distant metastasis in patients with resectable head and neck squamous cell carcinoma. In patients with laryngeal cancer, induction chemotherapy provides larynx preservation in responders to induction chemotherapy.
\end{abstract}

Keywords: Induction chemotherapy, Resectable head and neck squamous cell carcinoma, Randomized controlled trial, Meta-analysis

\section{Background}

Head and neck squamous cell carcinoma (HNSCC) ranks sixth among the most common cancers worldwide with an incidence of over 500,000 new cases each year [1]. Patients at an early stage clinical (stages I and II), are typically treated with single modality therapy, usually surgery or radiation therapy, with excellent disease control and long-term survival. For patients with more advanced disease, at clinical stages III and IV, comprehensive, sequential treatment regimens consisting of surgery, and/or

\footnotetext{
* Correspondence: zhonglp@hotmail.com

${ }^{\dagger}$ Equal contributors

Department of Oral Maxillofacial-Head Neck Oncology, Ninth People's Hospital, Shanghai Jiao Tong University School of Medicine, Shanghai Key Laboratory of Stomatology, No.639 Zhizaoju Rd, Shanghai, 200011, China
}

radiotherapy, with or without chemotherapy are mostly required [2]. However, the prognosis has not been significantly improved; the 5-year survival rate remains about $50 \%$ to $60 \%$, and is even lower in the patients at late clinical stages [3].

Induction chemotherapy has been investigated as a possible strategy to shrink or downstage locally advanced head and neck cancers, increase organ preservation rates, and/or reduce the risk of locoregional and/or distant recurrence, ultimately improving treatment outcomes. However, it should be noted that after induction chemotherapy locoregional treatment should be performed according to the original tumor borders, which should be marked with a tattoo or ink before treatment initiation; for example,

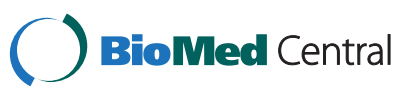


after preoperative induction chemotherapy, in order to remove the tumor completely, surgical resection should be performed according to the original tumor borders, regardless of the response to induction chemotherapy. Drug delivery is postulated to be better in untreated wellvascularized tumors before surgery and/or radiotherapy than that after surgery and/or radiotherapy. However, there is still debate about the clinical value of induction chemotherapy, especially for resectable HNSCC. Both positive and negative results from randomized controlled trials (RCTs) have been reported, and previous systematic reviews of these results have not merited a clear-cut benefit of induction chemotherapy on overall survival [4-7]. For locally advanced and resectable HNSCC, there is still no systemic analysis of the outcomes of induction chemotherapy followed by locoregional treatment compared to locoregional treatment alone, thus, we performed a metaanalysis of survival rate, locoregional control, distant metastasis, and toxicity.

\section{Methods}

\section{Eligibility criteria}

RCTs were eligible if they were studies of previously untreated patients with resectable non-metastatic HNSCC, comparing induction chemotherapy followed by locoregional treatment (comprising surgery, or radiotherapy or chemoradiotherapy, or surgery plus radiotherapy or chemoradiotherapy) versus locoregional treatment. The RCTs for larynx preservation were also eligible if they had compared radical surgery and radiotherapy versus induction chemotherapy, followed by radiotherapy or chemoradiotherapy in responders, or radical surgery and radiotherapy or chemoradiotherapy in non-responders. The RCTs were limited to those officially published in English, and based on patients recruited between 1 January 1965 and 31 December 2011. Tumor sites included the oral cavity, oropharynx, hypopharynx, and larynx with the exception of the nasopharynx.

\section{Search strategy}

Literature searching was conducted using the database of MEDLINE from 1965 to 2011 and EMBASE from 1980 to 2011. Reference lists and conference proceedings were also searched to identify possible additional RCTs. The following search codes were used: induction chemotherapy.tw, induc\$ chemotherapy.tw, neoadjuvant chemotherapy.tw, preoperative chemotherapy.tw, sequential chemotherapy.tw, adjuvant chemotherapy.tw, primary chemotherapy.tw, initial chemotherapy.tw, resectable.tw, operable.tw, head and neck.tw, oral.tw, pharyngeal.tw, oropharyngeal.tw, hypopharyngeal.tw, maxillofacial.tw, laryngeal.tw, paranasal sinus.tw, randomized controlled trials/, randomised-controlled-trial.pt, controlled-clinical -trial.pt, random allocation/, exp clinical trials/, clinical- trial.pt, random\$.ti,ab, comparative study/, follow-up studies/, prospective studies/.

\section{Data collection and analysis}

Suitability of studies for inclusion was independently assessed by two authors and any disagreement or lack of clarity was resolved through discussion. We developed a data extraction sheet based on the Cochrane Consumers and Communication Review Group data extraction template. The data, including patient number, age, sex, tumor site, tumor, node, metastasis (TNM) stage, were also extracted and checked by the two authors and disagreement was resolved through discussion. If agreement could not be reached between the two authors, a third author would participate in the discussion and so on, until reaching final agreement. The primary endpoint was overall survival. The secondary endpoints were disease-free survival, locoregional recurrence, and distant metastasis.

The time-to-event data from individual trials were summarized by the log hazard ratio (HR) and its variance. If the trials did not report this information directly, appropriate data, such as the $P$-value from the log-rank test were extracted to estimate the log $\mathrm{HR}$ and its variance [8], and the time-to-event data were extracted from the survival curves. Kaplan-Meier curves were read by the Engauge Digitizer version 4.1 (free software downloaded from http://sourceforge.net). Data combining was performed by RevMan version 5.1 (free software downloaded from http://www.cochrane.org). The log HR and its variance were pooled using an inverse variance weighted average, and the results were presented as an HR and 95\% CI.

DerSimonian-Laird random effect analysis was used to estimate the survival difference [9]. This method generates a combined survival difference and a 95\% CI with a heterogeneity test at each endpoint. Survival rate was derived from published survival curves if it was not provided explicitly in the text or tables. Subjects censored prior to each endpoint were subtracted from the denominators (number of patients during follow-up), giving a conservative CI for the summary statistic. Censored cases were counted by placing tick marks on survival curves when provided [10].

Heterogeneity was assessed by inspection of the forest plot, the Cochran chi-squared $\left(\chi^{2}\right)$ test, and the $I^{2}$ statistic percentage. A fixed effect approach was adopted unless there was significant evidence of unexplained heterogeneity, in which case a random effects approach was used.

\section{Results}

A total of 9,612 citations were identified from the database of MEDLINE and EMBASE, and there were 18 
RCTs that fulfilled the inclusion criteria. After review by all of the authors, 14 RCTs (2,107 patients) [11-27] were found to be eligible with complete and validated data for meta-analysis (Figure 1).

Among the 14 RCTs, comparison between the patients receiving induction chemotherapy followed by locoregional treatment (surgery and/or radiotherapy or chemoradiotherapy), and locoregional treatment alone (surgery and/or radiotherapy or chemoradiotherapy) was reported in 11 RCTs (1,505 patients) [11-23]. Comparison between induction chemotherapy followed by surgery in non-responders or radiotherapy/chemoradiotherapy in responders, and radical surgery and radiotherapy was reported in three RCTs, focusing on larynx preservation (602 patients) [24-27]. Although there were a few variations in these trials, such as period of study and duration of follow-up, the influence of study heterogeneity on the

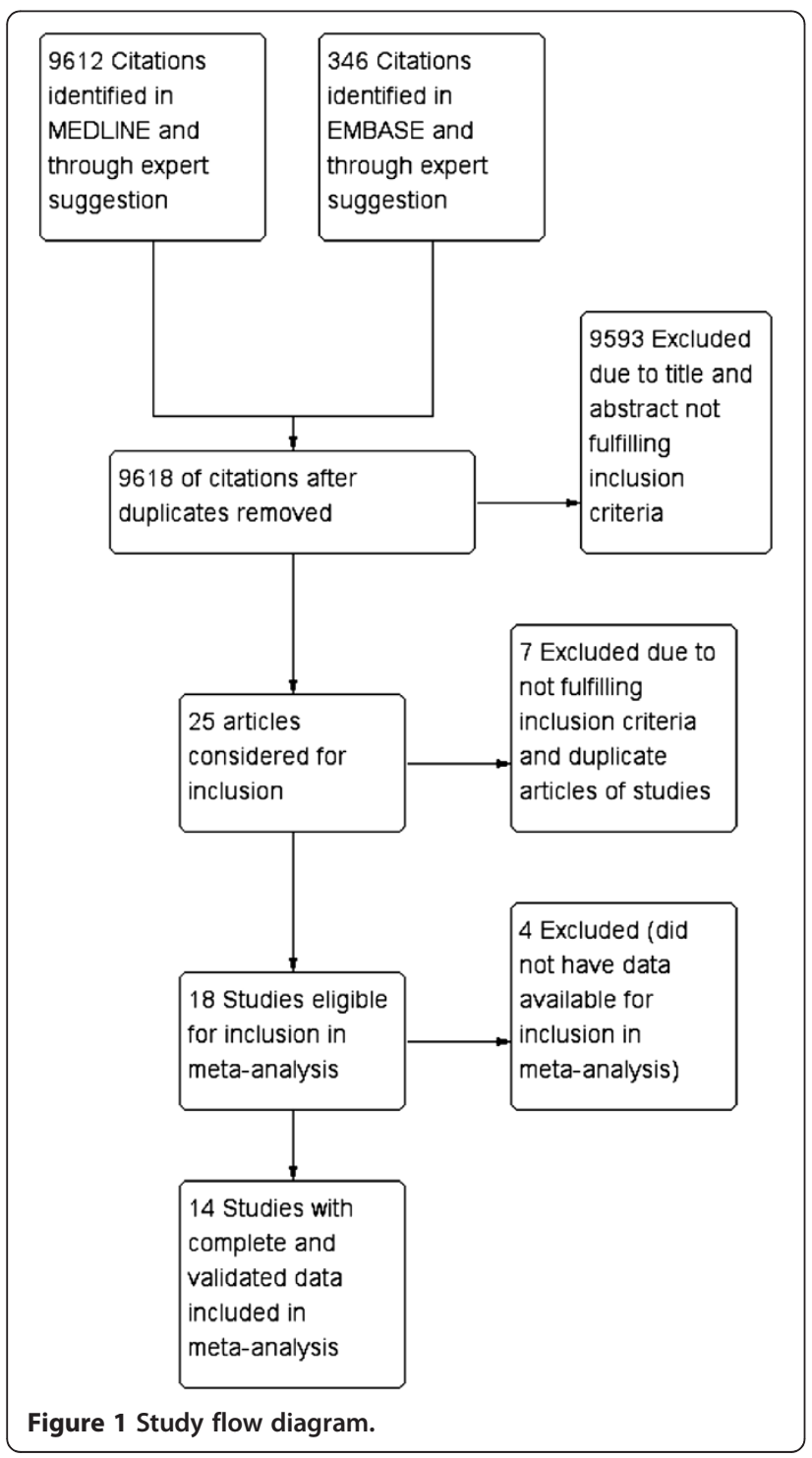

relative risk of disease-specific death was not significant $\left(I^{2}=0 \%, P=0.54\right)$. According to the toxicity of induction chemotherapy as reported in the trials, the most common toxicity effect was vomiting ( $8.5 \%$ to $24.5 \%)$, followed by leukopenia $(5.1 \%$ to $7.6 \%)$, mucositis $(0.2 \%$ to $8.2 \%)$, and thrombocytopenia $(1.7 \%$ to $7.7 \%)$; the induction chemotherapy-associated death rate was reported to be $0 \%$ to $5 \%$.

There was no significant difference in overall survival between patients treated with and without induction chemotherapy $(\mathrm{HR}=1.01,95 \% \mathrm{CI} 0.88,1.16, P=0.84)$, neither was there a significant difference according to the protocol of induction chemotherapy, such as cisplatin and 5-fluorouracil (PF), other platin-containing combinations, or multiple agents without platin (Figure 2). For diseasefree survival, there was no significant difference between the patients treated with or without induction chemotherapy $(\mathrm{HR}=0.97,95 \%$ CI 0.82, 1.15, $P=0.76$ ) (Figure 3 ).

In the three RCTs of laryngeal or hypopharyngeal cancer (602 patients) focusing on larynx preservation [24-27], compared to radical surgery followed by radiotherapy, the larynx could be preserved after induction chemotherapy in responders without decrease of overall survival $(\mathrm{HR}=1.21,95 \% \mathrm{CI} 0.72,2.03, P=0.47)$ or disease-free survival $(\mathrm{HR}=1.02,95 \% \mathrm{CI} 0.79,1.31, P=0.87)$.

There was no significant difference in long-term (5-year) locoregional recurrence rate between patients treated with or without induction chemotherapy (432 patients, ratio difference $=2 \%, 95 \% \mathrm{CI}-12 \%, 16 \%, P=0.76)$. However, among patients who developed distant metastases (700 patients), those treated with induction chemotherapy had a significantly lower long-term (5-year) rate of distant metastases ( $8 \%$ difference, 95\% CI 1\%, 16\%, $P=0.02$ ), compared to those treated without induction chemotherapy (Figure 4).

\section{Discussion}

In this study, for patients with locally advanced and resectable HNSCC, induction chemotherapy benefited these patients in terms of an $8 \%$ lower rate for the occurrence of distant metastases; however, induction chemotherapy did not improve overall survival, disease-free survival or locoregional control. The toxicity of induction chemotherapy was acceptable for further surgery, or radiotherapy or chemoradiotherapy.

Previous meta-analyses of both resectable and unresectable HNSCC [4-7] and this meta-analysis of resectable HNSCC confirm the effective decrease in the development of distant metastases in the patients without metastases at baseline (M0) treated with induction chemotherapy and locoregional treatment, compared to locoregional treatment alone. This is reasonable due to the effect of induction chemotherapy on peripheral, potentially metastatic tumor cells. 


\begin{tabular}{|c|c|c|c|c|c|c|c|}
\hline \multirow{3}{*}{$\begin{array}{l}\text { Study or Subgroup } \\
2.2 .1 \mathrm{PF}\end{array}$} & \multirow[b]{2}{*}{ log[Hazard Ratio] } & \multicolumn{2}{|r|}{ Experimental } & \multicolumn{2}{|l|}{ Control } & \multirow{2}{*}{$\begin{array}{l}\text { Hazard Ratio } \\
\text { IV, Fixed, } 95 \% \mathrm{Cl}\end{array}$} & \multirow{2}{*}{$\begin{array}{l}\text { Hazard Ratio } \\
\text { IV, Fixed, } 95 \% \mathrm{Cl}\end{array}$} \\
\hline & & SE & Total & Total & Weight & & \\
\hline & & & & & & & \\
\hline Volling 1994 & 0.1094 & 0.4859 & 49 & 47 & $2.1 \%$ & $1.12[0.43,2.89]$ & \\
\hline Richard 1998 & 0.9942 & 0.3618 & 36 & 32 & $3.7 \%$ & $2.70[1.33,5.49]$ & \\
\hline Lewin 1997 & 0.195 & 0.3254 & 37 & 30 & $4.6 \%$ & $1.22[0.64,2.30]$ & \\
\hline Paccagnella 2004 & 0.0797 & 0.3015 & 34 & 32 & $5.3 \%$ & $1.08[0.60,1.96]$ & \\
\hline Domenge 2000 & -0.4088 & 0.2508 & 31 & 73 & $7.7 \%$ & $0.66[0.41,1.09]$ & \\
\hline Licitra 2003 & 0.0615 & 0.2074 & 98 & 97 & $11.3 \%$ & $1.06[0.71,1.60]$ & \\
\hline Lefebvre 1996 & -0.1508 & 0.1867 & 103 & 99 & $13.9 \%$ & $0.86[0.60,1.24]$ & \\
\hline Veterans Affairs 1998 & 0.0035 & 0.1803 & 166 & 166 & $14.9 \%$ & $1.00[0.70,1.43]$ & \\
\hline Subtotal $(95 \% \mathrm{Cl})$ & & & 594 & 576 & $63.6 \%$ & $1.01[0.85,1.20]$ & \\
\hline \multicolumn{8}{|c|}{$\begin{array}{l}\text { Heterogeneity: } C \mathrm{C}^{2}=11.41, d f=?(P=0.12) ;\left.\right|^{2}=39 \% \\
\text { Test for overall effect: } Z=0.13(P=0.90)\end{array}$} \\
\hline \multirow{2}{*}{\multicolumn{8}{|c|}{ 2.2.2 polyCI with platin followed by Locoregional Treatment versus }} \\
\hline Kohno 2000 & 0.8436 & 0.866 & 13 & 11 & & & \\
\hline Maipang 1995 & -0.1407 & 0.4853 & 30 & 24 & $2.1 \%$ & $0.87[0.34,2.25]$ & \\
\hline Schuller 1988 & 0.2098 & 0.1903 & 82 & 76 & $13.4 \%$ & $1.23[0.85,1.79]$ & \\
\hline Subtotal $(95 \% \mathrm{Cl})$ & & & 125 & 111 & $16.1 \%$ & $1.21[0.86,1.70]$ & \\
\hline \multicolumn{8}{|c|}{$\begin{array}{l}\text { Heterogeneity: } \mathrm{Chi}^{2}=1.04, \mathrm{df}=2(P=0.59) ; I^{2}=0 \% \\
\text { Test for overall effect: } Z=1.10(P=0.27)\end{array}$} \\
\hline \multicolumn{8}{|c|}{ 2.2.3 polyCI without platin followed by Locoregional Treatment versus Locoregional Treatment alone for all studies } \\
\hline Richard 1991b & -0.1639 & 0.311 & 48 & 47 & $5.0 \%$ & $0.85[0.46,1.56]$ & \\
\hline Richard 1991a & -0.4985 & 0.2941 & 64 & 63 & $5.6 \%$ & $0.61[0.34,1.08]$ & \\
\hline Jortay 1990 & 0.1271 & 0.2241 & 89 & 98 & $9.7 \%$ & $1.14[0.73,1.76]$ & \\
\hline Subtotal $(95 \% \mathrm{Cl})$ & & & 201 & 208 & $20.3 \%$ & $0.89[0.66,1.20]$ & \\
\hline \multicolumn{8}{|c|}{$\begin{array}{l}\text { Heterogeneity: } \mathrm{Chi}^{2}=2.89, \mathrm{df}=2(P=0.24) ; \mathrm{I}^{2}=31 \% \\
\text { Test for overall effect: } Z=0.76(P=0.45)\end{array}$} \\
\hline Total $(95 \% \mathrm{Cl})$ & & & 920 & 895 & $100.0 \%$ & $1.01[0.88,1.16]$ & \\
\hline $\begin{array}{l}\text { Heterogeneity: } \mathrm{Chi}^{2}=1 \\
\text { Test for overall effect: } Z \\
\text { Test for subaroun diffe }\end{array}$ & $\begin{array}{l}11, d f=13(P=0.19) \\
=0.20(P=0.84) \\
\text { ences: } C h i^{2}=1.76 . d f\end{array}$ & $\begin{array}{l}f) ; I^{2}=24 \% \\
f=2(P=0\end{array}$ & $0.41) \cdot I^{2}=0 \%$ & & & & 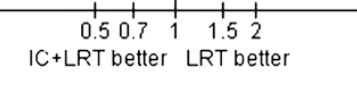 \\
\hline \multicolumn{8}{|c|}{$\begin{array}{l}\text { Figure } 2 \text { Forest plot of hazard ratios for overall survival and } 95 \% \mathrm{Cl} \text { in fourteen randomized controlled trials in patients with } \\
\text { resectable head and neck squamous cell carcinoma treated with induction chemotherapy followed by locoregional treatment, or } \\
\text { locoregional treatment alone. Richard } 1991 \mathrm{a}^{23} \text { is for cancer of the floor of the mouth, Richard } 1991 \mathrm{~b}^{23} \text { is for cancer of the posterior oral cavity } \\
\text { and oropharynx. Volling } 1994^{13} \text {, Richard } 1998^{27} \text {, Lewin } 1997^{14} \text {, Paccagnella } 2004^{11} \text {, Domenge } 2000^{15} \text {, Licitra } 2003^{16} \text {, Lefebvre } 1996^{24} \text {, Veterans } \\
\text { Affairs } 1998^{27} \text {, Kohno } 2000^{21} \text {, Maipang } 1995^{19} \text {, Schuller } 1988^{20} \text {, Jortay } 1990^{22} \text {. }\end{array}$} \\
\hline
\end{tabular}

In this study, with respect to overall survival, we found no significant benefit of induction chemotherapy in the patients with resectable HNSCC, even using the PF protocol, which has been reported to be beneficial to overall survival in other meta-analyses $[4,6,7]$. According to the site of primary lesions, most of patients receiving
PF induction chemotherapy in the present study were oral cancer patients; while the previous studies of induction chemotherapy in HNSCC patients included not only oral cancer, but also patients with oropharyngeal and hypopharyngeal cancer. As we know, for oral cancer patients with resectable lesions, radical surgery is

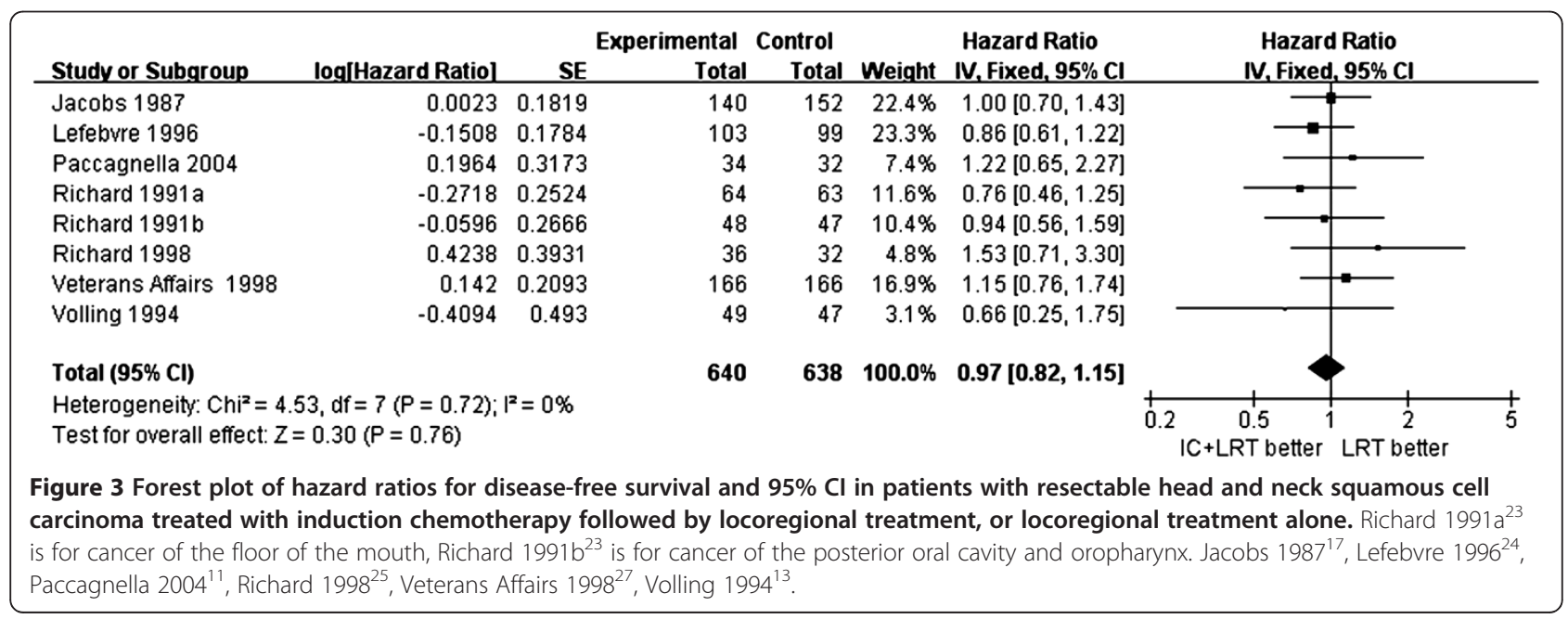




\begin{tabular}{|c|c|c|c|c|c|}
\hline Studv or Subgroup & 5-vear distant metastasis & SE & Weight & $\begin{array}{r}\text { 5-year distant metastasis } \\
\text { N. Fixed, 95\% Cl }\end{array}$ & $\begin{array}{c}\text { 5-year distant metastasis } \\
\text { IV, Fixed, } 95 \% \mathrm{Cl}\end{array}$ \\
\hline Hasegawa 1996 & -0.17 & 0.0768 & $23.3 \%$ & $-0.17[-0.32,-0.02]$ & $\longrightarrow$ \\
\hline Licitra 2003 & -0.0308 & 0.0775 & $22.9 \%$ & $-0.03[-0.18,0.12]$ & $\rightarrow$ \\
\hline Paccagnella 2004 & -0.2681 & 0.2225 & $2.8 \%$ & $-0.27[-0.70,0.17]$ & \\
\hline Richard 1991a & -0.0445 & 0.0632 & $34.4 \%$ & $-0.04[-0.17,0.08]$ & $=$ \\
\hline Richard 1991b & -0.0825 & 0.0911 & $16.6 \%$ & $-0.08[-0.26,0.10]$ & \\
\hline Total $(95 \% \mathrm{Cl})$ & & & $100.0 \%$ & $-0.08[-0.16,-0.01]$ & \\
\hline $\begin{array}{l}\text { Heterogeneity: } \mathrm{Chi}^{2} \\
\text { Test for overall effec }\end{array}$ & $\begin{array}{l}2.80, \mathrm{df}=4(P=0.59) ; I^{2}=0 \% \\
Z=2.24(P=0.02)\end{array}$ & & & & $\begin{array}{cccc}-0.2-0.1 & 0 & 0.1 & 0.2 \\
\text { IC }+ \text { LRT better } & \text { LRT better }\end{array}$ \\
\hline \multicolumn{6}{|c|}{$\begin{array}{l}\text { Figure } 4 \text { Forest plot of hazard ratios of distant metastasis-free survival and } 95 \% \mathrm{Cl} \text { in patients with resectable head and neck } \\
\text { squamous cell carcinoma treated with induction chemotherapy followed by locoregional treatment, or locoregional treatment alone. } \\
\text { Richard } 19911^{23} \text { is for cancer of the floor of the mouth, Richard } 1991 \mathrm{~b}^{23} \text { is for cancer of the posterior oral cavity and oropharynx. Hasegawa } \\
1996^{18} \text {, Licitra } 2003^{16} \text {, Paccagnella } 2004^{11} \text {. }\end{array}$} \\
\hline
\end{tabular}

considered as the standard of care, followed by postoperative radiotherapy or chemoradiotherapy, depending on the presence of intermediate/high risk features in the surgical specimen; and for patients with resectable locally advanced oropharyngeal and hypopharyngeal cancer, surgery, or radiotherapy or chemoradiotherapy, followed by radiotherapy or chemoradiotherapy is considered the standard of care. The efficiency of adding PF agents to standard care may differ between patients with oral cancer, and those with oropharyngeal or hypopharyngeal cancer. So, the effect of PF induction chemotherapy may differ in the patients with different primary tumor sites, and therefore, the primary tumor site might be considered before adding PF induction chemotherapy. It appears that induction chemotherapy could be more effective in oropharyngeal and hypopharyngeal cancer than in oral cancer. This could be due to various factors, such as high-risk human papilloma virus (HPV) infection, producing virus oncoproteins of E6 and E7, which are necessary for viral replication through their proliferation-stimulating activity, and play a key role in malignant transformation and maintenance; they are also sensitive to cytotoxic chemotherapy and DNA damage-induced apoptosis. Also, as we know, the incidence of HPV in patients with oropharyngeal cancer is higher than in patients with oral cancer. Based on the results of the present study, some factors might be considered to improve the prognosis in future clinical trials, such as insistence on radical surgery, even in patients with clinical response, in order to reduce locoregional failure and to improve survival, or optimization of the induction chemotherapy protocol by adding new or targeted drugs.

Recently, in two randomized phase III trials [3,28,29], a new induction chemotherapy protocol of a combination of docetaxel, cisplatin and 5-fluorouracil (TPF) followed by radiotherapy or chemoradiotherapy has been shown to improve survival compared to PF, and it is suggested as the preferred chemotherapy regimen when induction treatment is used for management of HNSCC patients. However, there is still little evidence from large clinical trials that the use of induction TPF prior to locoregional treatment improves survival when compared to locoregional treatment alone. Furthermore, it is unknown whether induction TPF improves outcomes when given prior to surgery in patients with locally advanced and resectable HNSCC. Several clinical trials of epidermal growth factor receptor inhibitors suggest the targeted drugs could improve locoregional control and survival in HNSCC patients with primary, recurrent or distant metastatic lesions; cetuximab, for example, is now firmly established as an active component of treatment for advanced HNSCC, alone and in combination with other modalities, including radiotherapy, platinumbased chemotherapy and induction therapy. Cetuximab has been approved by the Food and Drug Administration (FDA) USA, for HNSCC treatment in combination with radiotherapy for locally advanced, potentially curable disease, and as a single agent for incurable recurrent or metastatic disease [30-33]. Additional clinical trials are warranted to determine the benefit of adding an epidermal growth factor receptor (EGFR)-targeted agent in the setting of locally advanced and resectable HNSCC.

As we know, the different response to induction chemotherapy could lead to different survival, with good response always leading to good survival, bad response leading to poor survival [16]. Some predictive biomarkers reflecting the response to induction chemotherapy could be helpful for the next treatment choice, or in deciding whether induction chemotherapy should be performed, especially for resectable lesions. If the individual biomarkers predict bad response to induction chemotherapy, it should not be performed in those patients; otherwise, induction chemotherapy could benefit both patient response and survival. The biomarkers include DNA sequence mutations, epigenetic changes, and levels of messenger RNA or protein expression. For example, in a prospective study [34], p53 gene mutations are strongly associated with a poor risk of both objective 
and major response to PF-based induction chemotherapy, suggesting that patients with HNSCC should first be screened for $p 53$ mutations, before choosing the most appropriate treatment protocol based on the mutations.

For organ preservation, it has been well-recognized that in patients who respond to it, induction chemotherapy, followed by radiotherapy or chemoradiotherapy, instead of radical surgery, could benefit patients with laryngeal cancer by preserving the larynx, without a negative impact on overall survival and disease-free survival. For other organs, although the response rate to induction chemotherapy is relative high $(50 \%$ to $80 \%)$ in the resectable lesions, which provides a better chance to eradicate the locoregional lesions by radical surgery, there is no conclusive evidence that induction chemotherapy confers the benefit of organ preservation. A report by Licitra et al. [16] revealed that induction chemotherapy can reduce the number of patients requiring mandibulectomy and/or radiation therapy. However, there are no further reports on the differences in survival or locoregional recurrence between patients who do or do not undergo mandibulectomy and/or radiotherapy. In our opinion, in order to remove the tumor completely, emphasis should placed on surgical resection being performed according to the original tumor borders, which are marked with tattoo or ink before treatment initiation, regardless of the response to induction chemotherapy. In this study, there was no evidence of significant differences in relation to benefit for locoregional control between patients receiving or not receiving induction chemotherapy. Further trials are needed to resolve whether induction chemotherapy can lead to organ perseveration of non-laryngeal sites.

\section{Conclusions}

In conclusion, there is a significant benefit of induction chemotherapy in reducing distant metastases in patients with locally advanced and resectable HNSCC; however, there is no strong evidence of benefit in survival or locoregional control. In contrast, induction chemotherapy can be quite effective for preservation of the larynx. Further research on non-laryngeal organ preservation are encouraged using optimized induction chemotherapy protocols, and also evaluating molecular biomarkers that could help to identify those patients most likely, or unlikely to benefit from the addition of induction chemotherapy to their treatment regimen.

\footnotetext{
Abbreviations

EGFR: epidermal growth factor receptor; FDA: Food and Drug Administration; HNSCC: head and neck squamous cell carcinoma; HPV: human papilloma virus; RCT: randomized controlled trial; HR: hazard ratio; PF: cisplatin and 5fluorouracil; TNM: tumor node, metastasis; TPF: docetaxel cisplatin and 5fluorouracil.
}

\section{Competing interests}

The authors declare that they have no competing interests.

\section{Authors' contributions}

LZ and ZZ participated in the study design and coordination. CZ participated in the study coordination. JM, YL and XY participated in the literature search, data extraction and statistical analysis. All authors edited the manuscript and approved the final manuscript.

\section{Authors' information}

Co-corresponding author: Zhi-yuan Zhang.

\section{Acknowledgements}

This work was supported by research grants 81272979 and 30973344 from the National Natural Science Foundation of China.

Received: 24 October 2012 Accepted: 23 February 2013

Published: 14 March 2013

\section{References}

1. Parkin DM, Bray F, Ferlay J, Pisani P: Global cancer statistics, 2002. CA Cancer J Clin 2005, 55:74-108.

2. Forastiere AA: Head and neck cancer: overview of recent developments and future directions. Semin Oncol 2000, 27:1-4.

3. Posner MR, Hershock DM, Blajman CR, Mickiewicz E, Winquist E, Gorbounova V, Tjulandin S, Shin DM, Cullen K, Ervin TJ, Murphy BA, Raez LE, Cohen RB, Spaulding M, Tishler RB, Roth B, Viroglio Rdel C, Venkatesan V, Romanov I, Agarwala S, Harter KW, Dugan M, Cmelak A, Markoe AM, Read PW, Steinbrenner L, Colevas AD, Norris CM Jr, Haddad RI, TAX 324 Study Group: Cisplatin and fluorouracil alone or with docetaxel in head and neck cancer. N Engl J Med 2007, 357:1705-1715.

4. Pignon JP, Bourhis J, Domenge C, Designe L: Chemotherapy added to locoregional treatment for head and neck squamous-cell carcinoma: three meta-analyses of updated individual data. Lancet 2000, 355:949-955.

5. Monnerat C, Faivre S, Temam S, Bourhis J, Raymond E: End points for new agents in induction chemotherapy for locally advanced head and neck cancers. Ann Oncol 2002, 13:995-1006.

6. Pignon JP, le Maître A, Maillard E, Bourhis J, MACH-NC Collaborative Group: Meta-analysis of chemotherapy in head and neck cancer (MACH-NC): An update on 93 randomised trials and 17,346 patients. Radiother Oncol 2009, 92:4-14

7. Furness S, Glenny AM, Worthington HV, Pavitt $\mathrm{S}$, Oliver R, Clarkson JE, Macluskey M, Chan KK, Conway DI: Interventions for the treatment of oral cavity and oropharyngeal cancer: chemotherapy. Cochrane Database Syst Rev 2011, 4:CD006386.

8. Parmar MK, Torri V, Stewart L: Extracting summary statistics to perform meta-analyses of the published literature for survival endpoints. Stat Med 1998, 17:2815-2834.

9. DerSimonian R, Laird N: Meta-analysis in clinical trials. Control Clin Trials 1986, 7:177-188

10. Mitsudomi T, Hamajima N, Ogawa M, Takahashi T: Prognostic significance of p53 alterations in patients with non-small cell lung cancer: a metaanalysis. Clin Cancer Res 2000, 6:4055-4063.

11. Paccagnella A, Orlando A, Marchiori C, Zorat PL, Cavaniglia G, Sileni VC, Jirillo A, Tomio L, Fila G, Fede A, Endrizzi L, Bari M, Sampognaro E, Balli M, Gava A, Pappagallo GL, Fiorention MV: Phase III trial of initial chemotherapy in stage III or IV head and neck cancers: a study by the Gruppo di Studio sui Tumori della Testa e del Collo. J Nat/ Cancer Inst 1994, 86:265-272.

12. Zorat PL, Paccagnella A, Cavaniglia G, Loreggian L, Gava A, Mione CA, Boldrin F, Marchiori C, Lunghi F, Fede A, Bordin A, Da Mosto MC, Sileni VC, Orlando A, Jirillo A, Tomio L, Pappagallo GL, Ghi MG: Randomized phase III trial of neoadjuvant chemotherapy in head and neck cancer: 10-year follow-up. J Natl Cancer Inst 2004, 96:1714-1717.

13. Volling $P$, Schroder $M$, Muller R, Ebeling $\mathrm{O}$, Quirin $\mathrm{R}$, Stennert E: Induction chemotherapy in primary resectable head and neck tumors - a prospective randomized trial. Int J Oncol 1994, 4:909-914.

14. Lewin F, Damber $L$, Jonsson $H$, Andersson $T$, Berthelsen $A$, Biorklund $A$ Blomqvist E, Evensen JF, Hansen HS, Hansen O, Jetlund O, Mercke C, Modig H, Overgaard M, Rosengren B, Tausjo J, Ringborg U: Neoadjuvant chemotherapy with cisplatin and 5 -fluorouracil in advanced squamous cell carcinoma of the head and neck: a randomized phase III study. Radiother Oncol 1997, 43:23-28. 
15. Domenge $C$, Hill $C$, Lefebvre $J$, De Raucourt $D$, Rhein $B$, Wibault $P$, Marandas P, Coche-Dequeant B, Stromboni-Luboinski M, Sancho-Garnier H, Luboinski B, French Groupe d'Etude des Tumeurs de la Tete et du Cou (GETTEC): Randomized trial of neoadjuvant chemotherapy in oropharyngeal carcinoma. French Groupe d'Etude des Tumeurs de la Tete et du Cou (GETTEC). Br J Cancer 2000, 83:1594-1598.

16. Licitra L, Grandi C, Guzzo M, Mariani L, Lo Vullo S, Valvo F, Quattrone P, Valagussa P, Bonadonna G, Molinari R, Cantu G: Primary chemotherapy in resectable oral cavity squamous cell cancer: a randomized controlled trial. J Clin Oncol 2003, 21:327-333.

17. : Adjuvant chemotherapy for advanced head and neck squamous carcinoma. Final report of the Head and Neck Contracts Program. Cancer 1987, 60:301-311.

18. Hasegawa Y, Matsuura H, Fukushima M, Kano M, Shimozato K: Potential suppression of distant and node metastasis by neoadjuvant chemotherapy in advanced head and neck cancer: result of a randomized trial. Proc ASCO 1996, 15:318.

19. Maipang T, Maipang M, Geater A, Panjapiyakul C, Watanaarepornchai S, Punperk S: Combination chemotherapy as induction therapy for advanced resectable head and neck cancer. J Surg Oncol 1995, 59:80-85.

20. Schuller DE, Metch B, Stein DW, Mattox D, McCracken JD: Preoperative chemotherapy in advanced resectable head and neck cancer: final report of the Southwest Oncology Group. Lanyngoscope 1988, 98:1205-1211.

21. Kohno N, Ikari T, Kawaida M, Tanaka K, Kawaura M, Kano S, Nakamizo M: Survival results of neoadjuvant chemotherapy for advanced squamous cell carcinoma of the head and neck. Jpn J Clin Oncol 2000, 30:253-258.

22. Jortay A, Demard F, Dalesio O, Blanchet C, Desaulty A, Gehanno C, Lefebvre $J$, Molinari R, Traissac L, Dehesdin M, Kirkpatrick A: A randomized EORTC study on the effect of preoperative polychemotherapy in pyriform sinus carcinoma treated by pharyngolaryngectomy and irradiation. Results from 5 to 10 years. Acta Chir Belg 1990, 90:115-122.

23. Richard JM, Kramar A, Molinari R, Lefebvre JL, Blanchet F, Jortay A, SanchoGarnier H: Randomised EORTC head and neck cooperative group trial of preoperative intra-arterial chemotherapy in oral cavity and oropharynx carcinoma. Eur J Cancer 1991, 27:821-827.

24. Lefebvre JL, Chevalier D, Luboinski B, Kirkpatrick A, Collette L, Sahmoud T: Larynx preservation in pyriform sinus cancer: preliminary results of a European Organization for Research and Treatment of Cancer phase III trial. EORTC Head and Neck Cancer Cooperative Group. J Natl Cancer Inst 1996, 88:890-899.

25. Richard JM, Sancho-Garnier H, Pessey JJ, Luboinski B, Lefebvre JL, Dehesdin D, Stromboni-Luboinski M, Hill C: Randomized trial of induction chemotherapy in larynx carcinoma. Oral Oncol 1998, 34:224-228.

26. Induction chemotherapy plus radiation compared with surgery plus radiation in patients with advanced laryngeal cancer. The Department of Veterans Affairs Laryngeal Cancer Study Group. N Engl J Med 1991, 324:1685-1690.

27. Terrell JE, Fisher SG, Wolf GT: Long-term quality of life after treatment of laryngeal cancer. The Veterans Affairs Laryngeal Cancer Study Group. Arch Otolaryngol Head Neck Surg 1998, 124:964-971.

28. Vermorken BJ, Remenar E, Herpen VC, Gorlia T, Mesia R, Degardin M, Stewart JS, Jelic S, Betka J, Preiss JH, van den Weyngaert D, Awada A, Cupissol D, Kienzer HR, Rey A, Desaunois I, Bernier J, Lefebvre JL, EORTC 24971/TAX 323 Study Group: Cisplatin, fluorouracil, and docetaxel in unresectable head and neck cancer. N Engl J Med 2007, 357:1695-1704.

29. Lorch JH, Goloubeva O, Haddad RI, Cullen K, Sarlis N, Tishler R, Tan M, Fasciano J, Sammartino DE, Posner MR, TAX 324 Study Group: Induction chemotherapy with cisplatin and fluorouracil alone or in combination with docetaxel in locally advanced squamous-cell cancer of the head and neck: long-term results of the TAX 324 randomised phase 3 trial. Lancet Oncol 2011, 12:153-159.

30. Bonner JA, Harari PM, Giralt J, Azarnia N, Shin DM, Cohen RB, Jones CU, Sur R, Raben D, Jassem J, Ove R, Kies MS, Baselga J, Youssoufian H, Amellal N, Rowinsky EK, Ang KK: Radiotherapy plus cetuximab for squamous-cell carcinoma of the head and neck. N Engl J Med 2006, 354:567-578.

31. Vermorken JB, Mesia R, Rivera F, Remenar E, Kawecki A, Rottey S, Erfan J, Zabolotnyy D, Kienzer HR, Cupissol D, Peyrade F, Benasso M, Vynnychenko I, De Raucourt D, Bokemeyer C, Schueler A, Amellal N, Hitt R: Platinum-based chemotherapy plus cetuximab in head and neck cancer. $N$ Engl J Med 2008, 359:1116-1127.
32. Stewart JS, Cohen EE, Licitra L, Van Herpen CM, Khorprasert C, Soulieres D, Vodvarka P, Rischin D, Garin AM, Hirsch FR, Varella-Garcia M, Ghiorghiu S, Hargreaves L, Armour A, Speake G, Swaisland A, Vokes EE: Phase III study of gefitinib compared with intravenous methotrexate for recurrent squamous cell carcinoma of the head and neck. J Clin Oncol 2009, 27:1864-1871.

33. Mehra R, Cohen RB, Burtness BA: The role of cetuximab for the treatment of squamous cell carcinoma of the head and neck. Clin Adv Hematol Oncol 2008, 6:742-750

34. Temam S, Flahault A, Perie S, Monceaux G, Coulet F, Callard P, Bernaudin JF, St Guily JL, Fouret P: p53 gene status as a predictor of tumor response to induction chemotherapy of patients with locoregionally advanced squamous cell carcinomas of the head and neck. J Clin Oncol 2000, $18: 385-394$

doi:10.1186/1477-7819-11-67

Cite this article as: Ma et al:: Induction chemotherapy in patients with resectable head and neck squamous cell carcinoma: a meta-analysis. World Journal of Surgical Oncology 2013 11:67.

\section{Submit your next manuscript to BioMed Central and take full advantage of:}

- Convenient online submission

- Thorough peer review

- No space constraints or color figure charges

- Immediate publication on acceptance

- Inclusion in PubMed, CAS, Scopus and Google Scholar

- Research which is freely available for redistribution 